OPEN ACCESS

Edited by:

Guochang $\mathrm{Hu}$

University of Illinois at Chicago,

United States

Reviewed by:

Monowar Aziz,

Feinstein Institute for Medical

Research, United States

Claude Libert,

Flanders Institute for

Biotechnology, Belgium

*Correspondence:

Martin Wepler

martin.wepler@uni-ulm.de

Sabine Vettorazzi

sabine.vettorazzi@uni-ulm.de

tThese authors have contributed equally to this work

Specialty section:

This article was submitted to Inflammation,

a section of the journa

Frontiers in Immunology

Received: 12 September 2019 Accepted: 30 December 2019

Published: 23 January 2020

Citation:

Wepler M, Preuss JM, Merz T, Hartmann C, Wachter U, McCook O, Vogt J, Kress $S$, Gröger $M$, Fink $M$, Scheuerle A, Möller P, Calzia E,

Burret $U$, Radermacher $P$ Tuckermann JP and Vettorazzi S (2020) Impaired Glucocorticoid Receptor Dimerization Aggravates

LPS-Induced Circulatory and

Pulmonary Dysfunction.

Front. Immunol. 10:3152.

doi: 10.3389/fimmu.2019.03152

\section{Impaired Glucocorticoid Receptor Dimerization Aggravates LPS-Induced Circulatory and Pulmonary Dysfunction}

\author{
Martin Wepler ${ }^{1,2 \star t}$, Jonathan M. Preuss ${ }^{3 t}$, Tamara Merz ${ }^{1}$, Clair Hartmann ${ }^{1,2}$, \\ Ulrich Wachter ${ }^{1}$, Oscar McCook ${ }^{1}$, Josef Vogt ${ }^{1}$, Sandra Kress ${ }^{1}$, Michael Gröger ${ }^{1}$, \\ Marina Fink ${ }^{1}$, Angelika Scheuerle ${ }^{4}$, Peter Möller ${ }^{4}$, Enrico Calzia ${ }^{1}$, Ute Burret ${ }^{3}$, \\ Peter Radermacher ${ }^{1}$, Jan P. Tuckermann ${ }^{3}$ and Sabine Vettorazzi ${ }^{3 *}$
}

${ }^{1}$ Institute for Anesthesiologic Pathophysiology and Process Engineering, Ulm University, Ulm, Germany, ${ }^{2}$ Department of Anesthesiology, University Hospital, Ulm, Germany, ${ }^{3}$ Institute of Comparative Molecular Endocrinology (CME), Ulm University, Ulm, Germany, ${ }^{4}$ Institute of Pathology, University Hospital, Ulm, Germany

Background: Sepsis, that can be modeled by LPS injections, as an acute systemic inflammation syndrome is the most common cause for acute lung injury (ALI). ALI induces acute respiratory failure leading to hypoxemia, which is often associated with multiple organ failure (MOF). During systemic inflammation, the hypothalamus-pituitary-adrenal axis (HPA) is activated and anti-inflammatory acting glucocorticoids (GCs) are released to overcome the inflammation. GCs activate the GC receptor (GR), which mediates its effects via a GR monomer or GR dimer. The detailed molecular mechanism of the GR in different inflammatory models and target genes that might be crucial for resolving inflammation is not completely identified. We previously observed that mice with attenuated GR dimerization (GR $\left.{ }^{\mathrm{dim}} / \mathrm{dim}\right)$ had a higher mortality in a non-resuscitated lipopolysaccharide (LPS)- and cecal ligation and puncture (CLP)-induced inflammation model and are refractory to exogenous GCs to ameliorate ALI during inflammation.

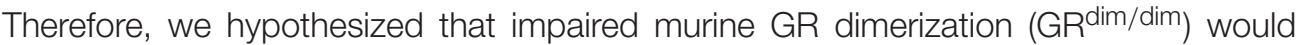
further impair organ function in LPS-induced systemic inflammation under human like intensive care management and investigated genes that are crucial for lung function in this setup.

Methods: Anesthetized $\mathrm{GR}^{\mathrm{dim} / \mathrm{dim}}$ and wildtype $\left(\mathrm{GR}^{+/+}\right)$mice were challenged with LPS (10 mg. $\mathrm{kg}^{-1}$, intraperitoneal) and underwent intensive care management ("lung-protective" mechanical ventilation, crystalloids, and norepinephrine) for $6 \mathrm{~h}$. Lung mechanics and gas exchange were assessed together with systemic hemodynamics, acid-base status, and mitochondrial oxygen consumption $\left(\mathrm{JO}_{2}\right)$. Western blots, immunohistochemistry, and real time quantitative polymerase chain reaction were performed to analyze lung tissue and inflammatory mediators were analyzed in plasma and lung tissue.

Results: When animals were challenged with LPS and subsequently resuscitated under intensive care treatment, GR ${ }^{\text {dim/dim }}$ mice had a higher mortality compared to $\mathrm{GR}^{+/+}$ mice, induced by an increased need of norepinephrine to achieve hemodynamic targets. 
After challenge with LPS, GR dim/dim mice also displayed an aggravated ALI shown by a more pronounced impairment of gas exchange, lung mechanics and increased osteopontin (Opn) expression in lung tissue.

Conclusion: Impairment of GR dimerization aggravates systemic hypotension and impairs lung function during LPS-induced endotoxic shock in mice. We demonstrate that the GR dimer is an important mediator of hemodynamic stability and lung function, possibly through regulation of Opn, during LPS-induced systemic inflammation.

Keywords: glucocorticoid receptor, lung function, endotoxic shock, inflammation, osteopontin

\section{INTRODUCTION}

Anti-inflammatory acting glucocorticoids (GCs) mediate their effects through the glucocorticoid receptor (GR). The GR is an intracellular, ligand-activated transcription factor, which regulates gene transcription as a protein dimer or monomer in several mechanisms: as a protein dimer it can bind palindromic DNA sequences (glucocorticoid response elements-GRE) or DNA half sites as a monomeric protein [GR monomer, (1)]. Further GR monomers potentially inhibit the activity of pro-inflammatory transcription factors, e.g., NF- $\mathrm{B}$ (2-5), AP-1 (6-8), or IRF-3 (9-11). This trans-repression is one major mechanism of GCs anti-inflammatory effects (12). However, it was recently shown that GC mediated anti-inflammatory responses also crucially require gene activation during inflammation (13). Indeed, mice with a point mutation in the GR DNA-binding domain $\left(\mathrm{GR}^{\mathrm{dim}}\right)$ exhibit less transactivation of GC-induced genes in vivo $(1,14)$ and fail to resolve inflammation in allergic (15), autoimmune (rheumatoid arthritis) (16), and systemic inflammation $(17,18)$.

Previously, we identified a novel mechanism by which GCs interfere with the pathogenesis of murine ALI, involving increased sphingosine kinase 1 (SphK1) gene expression and sphingosine-1-phosphate (S1P) production. The SphK1-S1P axis is recognized as an important regulator of endothelial barrier integrity that prevents lung inflammation $(19,20)$. In our previous study, we showed that the induction of SphK1 was GR dimerization dependent and therefore mice with an impaired GR dimerization $\left(\mathrm{GR}^{\mathrm{dim} / \mathrm{dim}}\right)$ had an impaired lung barrier function during systemic lipopolysaccharides (LPS)-induced inflammation and GC treatment (13).

However, all studies described so far were lacking simultaneous control of temperature, as well as hemodynamic, and respiratory support, which is standard in intensive care treatment. Moreover, if potential beneficial effects of GCs in the treatment of lung injury occur, it is yet not clear which mechanisms are involved. Therefore, we tested the effects of an impairment of the GR in a murine model of LPS-induced systemic inflammation when factors like temperature, hemodynamics, and respiration are controlled (intensive care management including measurements of hemodynamics, infusion of crystalloids and norepinephrine to achieve hemodynamic targets, lung-protective mechanical ventilation, determination of gas exchange) in the present study.
During intensive care management additional information about metabolic and hemodynamic parameters are observed that were missing in the former studies. We report that a congenital deficiency of the GR dimer aggravates hypotension, impairs lung function, and increases mortality in LPS-challenged mice.

\section{MATERIALS AND METHODS}

This study was approved by the federal authorities for animal research of the Regierungspräsidium Tübingen, BadenWuerttemberg, Germany, and performed in adherence with the National Institutes of Health Guidelines on the Use of Laboratory Animals and the European Union "Directive 2010/63 EU on the protection of animals used for scientific purposes". $\mathrm{GR}^{\mathrm{dim} / \mathrm{dim}}$ mice $\left(\mathrm{Nr} 3 \mathrm{c}^{\mathrm{tm} 3 \mathrm{Gsc}}\right)$ (21) were bred in a mixed background $(129 / \mathrm{SvEv} \times \mathrm{C} 57 \mathrm{BL} / 6)$ and housed in the animal facility at University Ulm. GR ${ }^{+/+}$littermate controls were used as wildtype mice. Animals were kept under standardized conditions and were equally distributed in terms of age and body weight.

\section{Implementation of General Anesthesia and Surgery}

Surgery for all animals included induction of anesthesia with sevoflurane (2.5\%; sevoflurane, Abbott, Wiesbaden, HE, Germany) as described previously $(22,23)$, followed by intraperitoneal injection (ip) of ketamine $\left(120 \mu \mathrm{g} \cdot \mathrm{g}^{-1}\right.$; KetanestS, Pfizer, New York City, NY), midazolam (1.25 $\mu \mathrm{g} \cdot \mathrm{g}^{-1}$; Midazolam-ratiopharm, Ratiopharm, Ulm, BW, Germany), and fentanyl $\left(0.25 \mu \mathrm{g} \cdot \mathrm{g}^{-1}\right.$; Fentanyl-hameln, Hameln Pharma Plus GmbH, Hameln, NI, Germany). Afterwards, animals were placed on a closed-loop-system for body temperature control $(22,23)$. Lung-protective mechanical ventilation using a small animal ventilator (FlexiVent, Scireq, MO, Canada) was performed via a tracheostomy $(22,23)$. Surgical instrumentation comprised catheters in the jugular vein, the carotid artery, and the bladder $(22,23)$. General anesthesia was titrated to guarantee complete tolerance against noxious stimuli and was sustained by continuous intravenous administration of ketamine, midazolam, and fentanyl to reach deep sedation. Animals were mechanically ventilated with ventilator settings being $\mathrm{FiO}_{2} 0.21 \%$, respiratory rate $150 \cdot \mathrm{min}^{-1}$, tidal volume of 6 $\mathrm{mL} \cdot \mathrm{kg}^{-1}$, and inspiratory/expiratory time ratio $1: 2$. Ventilation was modified to maintain an arterial $\mathrm{PaCO}_{2}$ between 30 and 
$45 \mathrm{mmHg}$, and positive end-expiratory pressure (PEEP) was adjusted according to the arterial $\mathrm{PaO}_{2}\left(\mathrm{PaO}_{2} / \mathrm{FiO}_{2}\right.$-ratio $>300$ mmHg: PEEP $=3 \mathrm{cmH}_{2} \mathrm{O} ; \mathrm{PaO}_{2} / \mathrm{FiO}_{2}$-ratio < $300 \mathrm{mmHg}$ : $\mathrm{PEEP}=5 \mathrm{cmH}_{2} \mathrm{O} ; \mathrm{PaO}_{2} / \mathrm{FiO}_{2}$-ratio < $200 \mathrm{mmHg}$ PEEP $\left.=8 \mathrm{cmH}_{2} \mathrm{O}\right)(22,23)$. Recruitment maneuvers $(5 \mathrm{~s}$ hold at $18 \mathrm{~cm} \mathrm{H} \mathrm{H}_{2} \mathrm{O}$ ) were repeated hourly to avoid any impairment of thoraco-pulmonary compliance due to anesthesia- and/or supine position-induced atelectasis.

\section{Induction of Systemic Inflammation}

After surgical instrumentation, systemic inflammation was induced by intraperitoneal (i.p.) injection of lipopolysaccharides (LPS=lipopolysaccharide from Escherichia coli [055:B5], L2880 Sigma, $10 \mathrm{mg} \cdot \mathrm{kg}^{-1}$, dissolved in $10 \mu \mathrm{l} \cdot \mathrm{g}^{-1}$ phosphate buffered saline $[\mathrm{PBS}])$. Mice were then resuscitated with crystalloids (30 $\mu \mathrm{l} \cdot \mathrm{g}^{-1} \cdot \mathrm{h}^{-1}$, Jonosteril, Braun Medical, Melsungen, HE, Germany). As soon as the mean arterial blood pressure (MAP) dropped below $55 \mathrm{mmHg}$, infusion of norepinephrine was started to reach a MAP $>55 \mathrm{mmHg}$ during the $6 \mathrm{~h}$ of resuscitation (maximum infusion rate $1.5 \mu \mathrm{g} \cdot \mathrm{h}^{-1}$ ). If blood pressure declined despite increasing doses of norepinephrine, the experiment was terminated. $\mathrm{GR}^{+/+}$mice, which received vehicle $\left(10 \mu \mathrm{l} \cdot \mathrm{g}^{-1} \mathrm{PBS}\right)$ with subsequent resuscitation, served as controls.

\section{Parameters of Lung Mechanics, Hemodynamics, Gas Exchange, and Metabolism}

Systemic hemodynamics, body temperature, and static thoracopulmonary compliance were recorded hourly. Blood gas tensions, acid-base status, glycaemia, and lactatemia were assessed at the end of the resuscitation period via aterial blood gas analysis (ABL800 Felx; Radiometer, Krefeld, Germany) (22, 23). At the end of the experiment, animals were exsanguinated, blood and lung tissue were taken immediately thereafter, and prepared for further analyses $(22,23)$. All lung tissue was utilized due to organ size. The left lung was harvested for histology and IHC, whereas the right lung served for immunoblotting, expression analysis, and cytokine and chemokine evaluation.

\section{Histological Analysis of Lung Tissue}

Histological analysis of lung tissue was independently performed by two experienced pathologists (AS and PM) blinded for group assignment. Similar to previous studies (23), analyzed criteria comprised thickening of alveolar membranes, dystelectasis, emphysema, and inflammatory cell (lymphocytes) infiltration. These parameters were scored from 0 (absent), 1 (hardly detectable), 2 (rare), 3 (minor), 4 (moderate), to 5 (extensive).

\section{Mitochondrial Respiration}

Mitochondrial respiratory capacity was determined via highresolution respirometry with a clark-electrode-based system (Oxygraph 2k, OROBOROS Instruments Corp., Innsbruck, Austria) as described previously (22). Post-mortem heart, muscle, liver, and brain biopsies were mechanically homogenized in Mir05 (respiration medium). Mir05 is composed of $0.5 \mathrm{mM}$ EGTA, $3 \mathrm{mM} \mathrm{MgCl}_{2} \cdot 6 \mathrm{H}_{2} \mathrm{O}, 60 \mathrm{mM}$ Lactobionic acid, $20 \mathrm{mM}$ Taurine, $10 \mathrm{mM} \mathrm{KH}{ }_{2} \mathrm{PO}_{4}, 20 \mathrm{mM}$ HEPES, $110 \mathrm{mM}$ Sucrose,
$1 \mathrm{~g} \cdot \mathrm{L}^{-1}$ bovine serum albumin). $1.5-2 \mathrm{mg}$ of tissue (1.5 $\mathrm{mg}$ : heart, $2 \mathrm{mg}$ tissue: muscle, liver, and brain) were added to the Oxygraph chamber. By addition of a defined sequence of substrates and inhibitors, various states of mitochondrial function could be assessed. Complex I activity was determined after addition of $10 \mathrm{mM}$ pyruvate, $10 \mathrm{mM}$ glutamate, $5 \mathrm{mM}$ malate, and $5 \mathrm{mM}$ ADP. Ten micrometers cytochrome $\mathrm{c}$ was added to check for mitochondrial integrity. Maximum oxidative phosphorylation (OxPhos) was evaluated after subsequent addition of $1 \mathrm{mM}$ octanoyl-carnitine and $10 \mathrm{mM}$ succinate. Leak compensation was assessed after inhibition of the ATPsynthase by $2.5 \mu \mathrm{M}$ oligomycin, followed by stepwise titration of the uncoupling agent Carbonyl cyanide-4-(trifluoromethoxy)phenylhydrazone (FCCP, final concentration $1.5 \mu \mathrm{M}$ ) to reach maximum respiratory activity of the electron transfer system in the uncoupled state (ETS).

\section{Western Blot}

The lung was dissected at the end of the experiment and frozen on dry ice. The tissue was homogenized in EDTAfree lysis buffer with tissue homogenisator (Precellys ${ }^{\circledR}$ ). Total protein concentration was determined using Pierce ${ }^{\circledR}$ BCA Protein Assay Kit (23225). Proteins were separated by SDSPAGE and blotted on nitrocellulose membrane using the TransBlot Turbo system (BioRad). Osteopontin was detected with anti-osteopontin primary antibody (mouse anti-mouse, LFMb14, Santa Cruz Biotechnology Inc., sc-73631) diluted 1:500. Vincullin was detected as loading control using anti-vincullin primary antibody (mouse anti-mouse, Santa Cruz Biotechnology Inc., sc-73614) diluted 1:1.000. Primary antibody incubation was done overnight at $4^{\circ} \mathrm{C}$. Secondary antibody (rabbit antimouse, HRP coupled polyclonal Ig, Dako, P0161) was diluted 1:10.000 and incubated $1 \mathrm{~h}$ at room temperature. Membrane blocking and dilutions were done with 5\% BSA. Except for the last washing step which was done with $1 \mathrm{x}$ TBS, $0.1 \%$ TBST was used. Blots were developed using immobilion forte WBLUF0500 (Merck Millipore) and ImageLab software (version 5.2). Osteopontin abundancy was quantified using ImageJ (version $1.52 \mathrm{a}$ ) by determination of mean signal intensity of osteopontin normalized to mean intensity of vincullin.

\section{Immunohistochemistry}

The left lung was formalin-fixed and embedded in paraffin for immunohistochemistry analysis. Immunohistochemistry (IHC) for extravascular albumin content (anti-albumin rabbit polyclonal \#16475-1-AP, Proteintech, USA) was performed as described previously (24). Primary antibodies were detected by secondary anti-rabbit antibody conjugated to AP (Alkaline Phosphatase-conjugated antibody; Jackson, ImmunoResearch, West Grove, $\mathrm{Pa}$ ) and visualized with a red chromogen (Darko REAL Detection System Chromogen Red), and Mayers hematoxylin (Sigma, Taufkirchen, Germany). Visualization was performed using the Zeiss Axio Imager A1 microscope (Zeiss, Jena, TH, Germany). Four distinct $800.000 \mathrm{~mm}^{2}$ regions were quantified for intensity of signal by using the Axio Vision 4.8 software. Results are presented as mean densitometric sum red $(24,25)$. 


\section{Cell Culture}

The primary bone marrow-derived macrophages (BMDMs) were isolated from humerus, femur and tibia of 8-13 weeks old $\mathrm{GR}^{+/+}$and $\mathrm{GR}^{\mathrm{dim} / \mathrm{dim}}$ mice as described previously (18). Briefly, cells were cultured until day 7 in DMEM (D5671, sigma) supplemented with $10 \%$ fetal bovine serum (FBS, F7524, sigma), 30\% L929-cell conditioned medium, 1\% Penicillin / Streptomycin (P0781, sigma), 1\% L-Glutamine (G7513, sigma), 1\% Sodium Pyruvate (S8636, sigma) at $37^{\circ} \mathrm{C}$ and $5 \% \mathrm{CO}_{2}$. All BMDMs were treated with PBS as control and LPS (100 ng/ml, L6529, sigma) for the indicated time points. Osteopontin Elisa (R\&D System) was performed with the supernatant of $\mathrm{GR}^{+/+}$and $\mathrm{GR}^{\operatorname{dim} / \operatorname{dim}}$ BMDMs.

\section{Analysis of Relative mRNA Levels}

For quantitative real-time PCR analysis (qRT-PCR), RNA was extracted from lungs by homogenization with tissue homogenisator (Precellys ${ }^{\circledR}$ ) in Trizol (invitrogen) following the manufacturer's instructions. RNA quality was checked using the nanodrop (thermofisher). DNaseI-treated RNA (1 $\mu \mathrm{g})$ was used to generate cDNA by oligo(dT) priming. qRT-PCR was performed with the ViiA ${ }^{\text {TM }} 7$ Realtime PCR System (Life technologies) using a Platinum SYBR Green (Invitrogen) and analyzed with the QuantStudio Realtime-PCR software using the $\Delta \Delta \mathrm{CT}$ method. $\beta$-Actin and Ribosomal protein $L$ (Rpl) served as housekeeping genes. The specific primers were obtained from Sigma with the sequences listed in Table 1.

\section{Measurements of Cytokine and Chemokine Concentrations}

Bio-Plex Pro Mouse Cytokine 23-plex Assay (Group I) (Biorad) was used to measure 23 cytokines, chemokines and growth factors simultaneously in the plasma. The Bio-Plex Assay was conducted according to the manufacturer's protocol. The assay was performed with Bio-Plex 200 machine (Biorad) and analyzed with the Bio-Plex Manager TM 6.1 software (Biorad).

\section{Statistical Analysis}

Unless stated otherwise, all data are presented as median (25th and 75th percentile). Data sets were analyzed using nonparametric statistics, i.e., Mann-Whitney $U$-test (one factor, two independent samples) or Kruskal-Wallis test with posthoc Dunn's comparison testing (one factor, four independent

TABLE 1 | Specific primers for quantitative real-time PCR analysis (qRT-PCR).

\begin{tabular}{lll}
\hline Gene & Forward primer & Reverse primer \\
\hline$\beta$-Actin & GCACCAGGGTGTGATGGTG & CCAGATCTTCTCCATGTCGTCC \\
I1- $\beta$ & GGCTGTGGAGAAGCTGTGGCA & GGGTCCGACAGCACGAGGCT \\
I-6 & AAACCGCTATGAAGTTCCTCTCTGC AGCCTCCGACTTGTGAAGTGGT \\
I-10 & CAGAGCCACATGCTCCTAGA & TGTCCAGCTGGTCCTTTGTT \\
Rpl & CCTGCTGCTCTCAAGGTT & TGGCTGTCACTGCCTGGTACTT \\
Tnfo & AGGGGCCACCACGCTCTTCT & TGAGTGTGAGGGTCTGGGCCAT \\
Sphkl & CCAAGTGCACCCAAACTACC & GCCCCACCTTCTAGCTTTCT
\end{tabular}

samples). $P<0.05$ were considered statistically significant. Quantitative graphical presentations and statistical analyses were accomplished by using GraphPad Prism 7 (GraphPad Software Inc., La Jolla, Calif).

\section{RESULTS}

\section{GR Dimerization Mediates Stability of Hemodynamics, Acid-Base Status, and Mitochondrial Respiration After LPS Challenge}

To examine the effects of an impaired GR dimerization during resuscitation in LPS-induced systemic inflammation, hemodynamics, metabolic parameters, and mitochondrial respiration were investigated. Hemodynamic stability was defined as MAP >55 $\mathrm{mmHg}$ and preserved via infusion of crystalloids and, if necessary, norepinephrine (maximum infusion rate $\left.1.5 \mu \mathrm{g} \cdot \mathrm{h}^{-1}\right)$. Therefore, in some mice $\left(\mathrm{GR}^{+/+} \mathrm{PBS}\right.$ $n=0, \mathrm{GR}^{\operatorname{dim} / \operatorname{dim}} \mathrm{PBS} n=1, \mathrm{GR}^{+/+} \mathrm{LPS} n=1, \mathrm{GR}^{\operatorname{dim} / \operatorname{dim}} \mathrm{LPS} n$ $=5$ ), the experiment had to be terminated due to hemodynamic instability despite increasing norepinephrine doses, which lead to MAP values below $55 \mathrm{mmHg}$. After LPS-challenge, $\mathrm{GR}^{\mathrm{dim} / \mathrm{dim}}$ mice had a trend toward a lower MAP when compared to $\mathrm{GR}^{+/+}$mice (Table 2). In line with the compromised systemic hemodynamics, norepinephrine requirements in $\mathrm{GR}^{\mathrm{dim} / \mathrm{dim}}$ mice challenged with LPS were significantly higher when compared to LPS-challenged $\mathrm{GR}^{+/+}$animals (Figure 1 and Table 2). In $\mathrm{GR}^{\mathrm{dim} / \mathrm{dim}}$ mice, a challenge with LPS led to an increase of lactate levels at the end of the resuscitation phase, and, consequently, to a more pronounced decrease in base excess (BE) compared to $\mathrm{GR}^{+/+}$mice, suggesting an aggravation of metabolic acidosis (Table 2). Because hyperlactatemia may be linked to disturbances in mitochondrial respiration $(26,27)$, important metabolic organs like muscle, heart, liver and brain were investigated for mitochondrial respiration in the current study. In LPS-challenged GR ${ }^{\mathrm{dim} / \mathrm{dim}}$ mice, oxygen flux during maximal coupled mitochondrial respiration (OxPhos) was decreased in heart tissue when compared to vehicle treated $\mathrm{GR}^{\mathrm{dim} / \mathrm{dim}}$ mice, whereas in $\mathrm{GR}^{+/+}$animals $\mathrm{OxPhos}$ was not changed between PBS and LPS-challenge (Figure 2A), suggesting a disturbed mitochondrial function in the heart of $\mathrm{GR}^{\mathrm{dim} / \mathrm{dim}}$ animals. In the liver tissue, oxygen flux during maximal mitochondrial respiration and during inhibited ATP synthase in the coupled state (LEAK) was higher in LPSchallenged than in vehicle challenged $\mathrm{GR}^{+/+}$mice (Figure $2 \mathrm{~B}$ ), suggesting an increased mitochondrial respiratory capacity in these animals. However, in the muscle and brain mitochondrial respiration was not changed neither in $\mathrm{GR}^{\mathrm{dim} / \mathrm{dim}}$ nor in $\mathrm{GR}^{+/+}$ animals during PBS- or LPS-challenge under resuscitation (Figures 2C,D). In summary, the impaired dimerization of the GR results in higher noradrenaline requirements and therefore compromised systemic hemodynamics as well as a more pronounced lactic acidosis and altered mitochondrial respiration during LPS-challenge. 
TABLE 2 | Hemodynamic and metabolic measurements as well as parameters of lung function in GR ${ }^{\text {dim/dim }}$ and $\mathrm{GR}^{+/+}$mice intraperitoneally challenged with lipopolysaccharide (LPS) or vehicle (phosphate buffered saline, PBS) at the end of the experiment.

\begin{tabular}{|c|c|c|c|c|}
\hline \multirow[t]{2}{*}{ Parameters } & \multicolumn{4}{|c|}{ Resuscitation (IV crystalloids and norepinephrine) } \\
\hline & $\begin{array}{c}\mathrm{GR}^{+/+} \\
+ \\
\text {Vehicle } \\
(n=8)\end{array}$ & $\begin{array}{c}\text { GR }^{\text {dim/dim }} \\
+ \\
\text { Vehicle } \\
(n=7)\end{array}$ & $\begin{array}{c}\mathrm{GR}^{+/+} \\
+ \\
\mathrm{LPS} \\
(n=9)\end{array}$ & $\begin{array}{c}\text { GR }^{\text {dim/dim }} \\
+ \\
\text { LPS } \\
(n=11)\end{array}$ \\
\hline $\begin{array}{l}\text { Bodyweight } \\
\text { [g] }\end{array}$ & $26.7(23.0 ; 31.6)$ & $24.6(20.6 ; 32.7)$ & $29.0(26.6 ; 31.1)$ & $24.0(22.7 ; 28.2)$ \\
\hline $\begin{array}{l}\text { Mean arterial pressure } \\
{[\mathrm{mmHg}]}\end{array}$ & $61(56 ; 65)$ & $54(52 ; 61)$ & $56(49 ; 58)$ & $49(43 ; 51)$ \\
\hline $\begin{array}{l}\mathrm{PaCO}_{2} \\
{[\mathrm{mmHg}]}\end{array}$ & $37(30 ; 45)$ & $41(39 ; 44)$ & $34(33 ; 47)$ & $43(40 ; 46)$ \\
\hline $\begin{array}{l}\text { Minute ventilation } \\
{\left[\mathrm{mL} \cdot \mathrm{kg}^{-1} \cdot \mathrm{min}^{-1}\right]}\end{array}$ & $905(838 ; 1,058)$ & $1,000(980 ; 1,080)$ & $1,000(960 ; 1,040)$ & $1,060(980 ; 1,170)$ \\
\hline Arterial pH & $7.28(7.26 ; 7.34)$ & $7.23(7.19 ; 7.28)$ & $7.14(7.12 ; 7.32)$ & $7.12(6.99 ; 7.20)$ \\
\hline $\begin{array}{l}\text { Arterial base excess } \\
{\left[\mathrm{mmol} \cdot \mathrm{L}^{-1}\right]}\end{array}$ & $-8.4(-11.3 ;-5.6)$ & $-7.9(-10.5 ;-7.4)$ & $-11.0(-13.2 ;-10.2)$ & $-14.5(-19.9 ;-12.0)^{\#}$ \\
\hline $\begin{array}{l}\text { Lactate } \\
{\left[\mathrm{mmol} \cdot \mathrm{L}^{-1}\right]}\end{array}$ & $1.1(0.8 ; 1.6)$ & $1.5(1.2 ; 2.1)$ & $2.8(2.1 ; 3.1)$ & $5.3(3.9 ; 6.6) \#$ \\
\hline $\begin{array}{l}\text { Hemoglobin } \\
{\left[g \cdot d L^{-1}\right]}\end{array}$ & $8.7(8.3 ; 10.6)$ & $9.0(8.6 ; 11.4)$ & $8.2(7.3 ; 10.1)$ & $9.0(8.0 ; 9.7)$ \\
\hline $\begin{array}{l}\text { Urinary output } \\
{[\mu \mathrm{L}]}\end{array}$ & $1,796(997 ; 2,413)$ & $2,309(1,494 ; 3,628)$ & $881(646 ; 1,906)$ & $969(514 ; 1,060)^{\#}$ \\
\hline
\end{tabular}

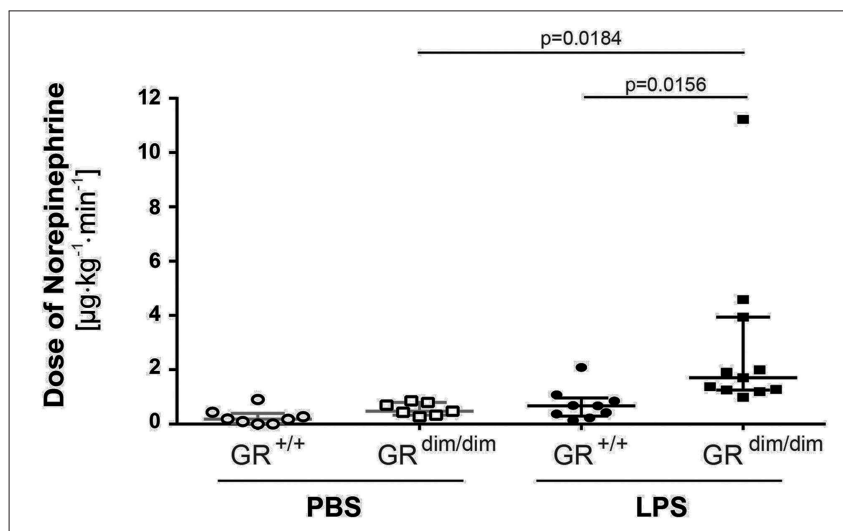

FIGURE 1 | Doses of norepinephrine in mechanically ventilated GR ${ }^{\mathrm{dim}} / \mathrm{dim}$ and $\mathrm{GR}^{+/+}$mice intraperitoneally challenged with lipopolysaccharides (LPS) or vehicle (PBS) and resuscitated (crystalloids, norepinephrine) for $6 \mathrm{~h}$. Norepinephrine was titrated intravenously during resuscitation to keep systemic mean arterial blood pressure above $55 \mathrm{mmHg}$. LPS = lipopolysaccharide from Escherichia coli [055:B5], $10 \mathrm{mg} \cdot \mathrm{kg}^{-1}$, dissolved in 10 $\mu \mathrm{l} \cdot \mathrm{g}^{-1}$ phosphate buffered saline (PBS). GR ${ }^{+/+}$mice challenged with PBS: $n$ $=8, \mathrm{GR}^{\mathrm{dim} / \mathrm{dim}}$ mice challenged with PBS: $n=7, \mathrm{GR}^{+/+}$mice challenged with LPS: $n=9$, GR dim/dim mice challenged with LPS: $n=11$. Data is presented as median (25th and 75th percentile and minimum/maximum).

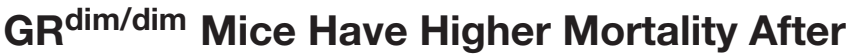 LPS Challenge With Subsequent Resuscitation}

In LPS-challenged mice with subsequent resuscitation for a maximum of $6 \mathrm{~h}$ (lung-protective mechanical ventilation, hemodynamic measurements, crystalloid and norepinephrine infusion to keep hemodynamic stability), mortality was significantly higher in $\mathrm{GR}^{\mathrm{dim} / \mathrm{dim}}$ mice when compared to $\mathrm{GR}^{+/+}$animals (Supplementary Figure 1).

\section{No Differences in Most Plasma Cytokines $6 \mathrm{~h}$ After LPS Challenge and Resuscitation}

After LPS-challenge, the concentration of Il-1 $\alpha$ in plasma increased in $\mathrm{GR}^{\mathrm{dim} / \mathrm{dim}}$, but not in $\mathrm{GR}^{+/+}$mice. In contrast, concentrations of Il-2, Eotaxin, and Ifn $\gamma$ only increased in $\mathrm{GR}^{+/+}$mice, but not in $\mathrm{GR}^{\mathrm{dim} / \mathrm{dim}}$ mice, however, all are expressed on a low level (Table 3). Pro-inflammatory plasma cytokines like Il1- $\beta$ (Figure 3A), Il-6 (Figure 3B), and Tnf $\alpha$ (Figure 3C) were significantly induced in both genotypes after LPS challenge, demonstrating that the intensive care management and resuscitation does not increase basal level of these inflammatory cytokines. 


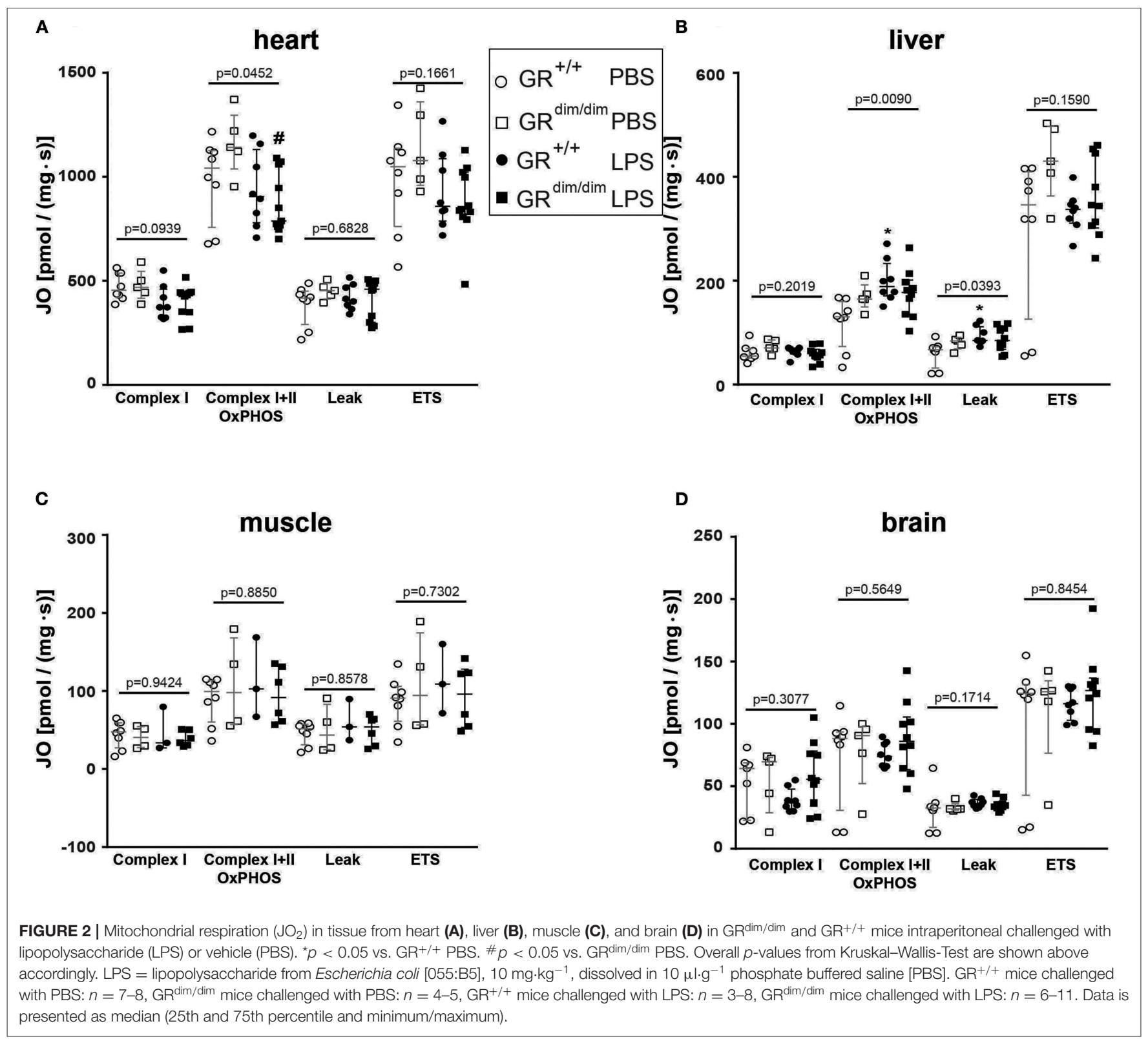

\section{Lung Function Is Impaired in GR ${ }^{\operatorname{dim} / \operatorname{dim}}$ Mice During Intensive Care Treatment}

Lung compliance as a marker for lung mechanics was reduced in PBS-treated $\mathrm{GR}^{\mathrm{dim} / \mathrm{dim}}$ mice in comparison to PBStreated $\mathrm{GR}^{+/+}$animals (Figure 4A). A significantly lower lung compliance was observed in $\mathrm{GR}^{\mathrm{dim} / \mathrm{dim}}$ mice compared to $\mathrm{GR}^{+/+}$ controls during LPS-challenge (Figure 4A). In line with a lower lung compliance, GR ${ }^{\mathrm{dim} / \mathrm{dim}}$ mice had a reduced Horovitz-Index (partial pressure of oxygen in the arterial blood, divided by the inspiratory concentration of oxygen) as a marker for systemic oxygenation (Table 2 ). However, $\mathrm{GR}^{+/+}$animals did not show any significant changes in lung compliance or Horovitz-Index after LPS-challenge in comparison to PBS-challenged $\mathrm{GR}^{+/+}$ animals (Figure 4A and Table 2), suggesting a more severe lung dysfunction in response to LPS-challenge in GR dimerization impaired mice. The histological evaluation of lung tissue revealed no significant differences in the total score between the corresponding groups, however the $\mathrm{GR}^{\mathrm{dim} / \mathrm{dim}}$ animals had a slight elevated total score (Table 4). Immunohistochemistry (IHC) for albumin extravasation showed a higher expression in lung tissue after LPS-challenge in $\mathrm{GR}^{\mathrm{dim} / \mathrm{dim}}$ mice compared to $\mathrm{GR}^{+/+}$mice, whereas no difference was observed in extravascular albumin expression between $\mathrm{GR}^{\mathrm{dim} / \mathrm{dim}}$ and $\mathrm{GR}^{+/+}$ mice after vehicle treatment (Figure 4B). In previous studies, increased albumin extravasation and vascular leakage was accompanied by a reduced expression of Sphk1 dependent on the GR dimerization during inflammation (13). In the present study, LPS-challenged $\mathrm{GR}^{+/+}$mice showed increased Sphk1 expression 
TABLE 3 | Concentrations of cytokines in plasma of $\mathrm{GR}^{\mathrm{dim} / \mathrm{dim}}$ and $\mathrm{GR}^{+/+}$mice intrapoeritoneal challenged with lipopolysaccharide (LPS) or vehicle (phosphate buffered saline, PBS) measured at the end of the experiment.

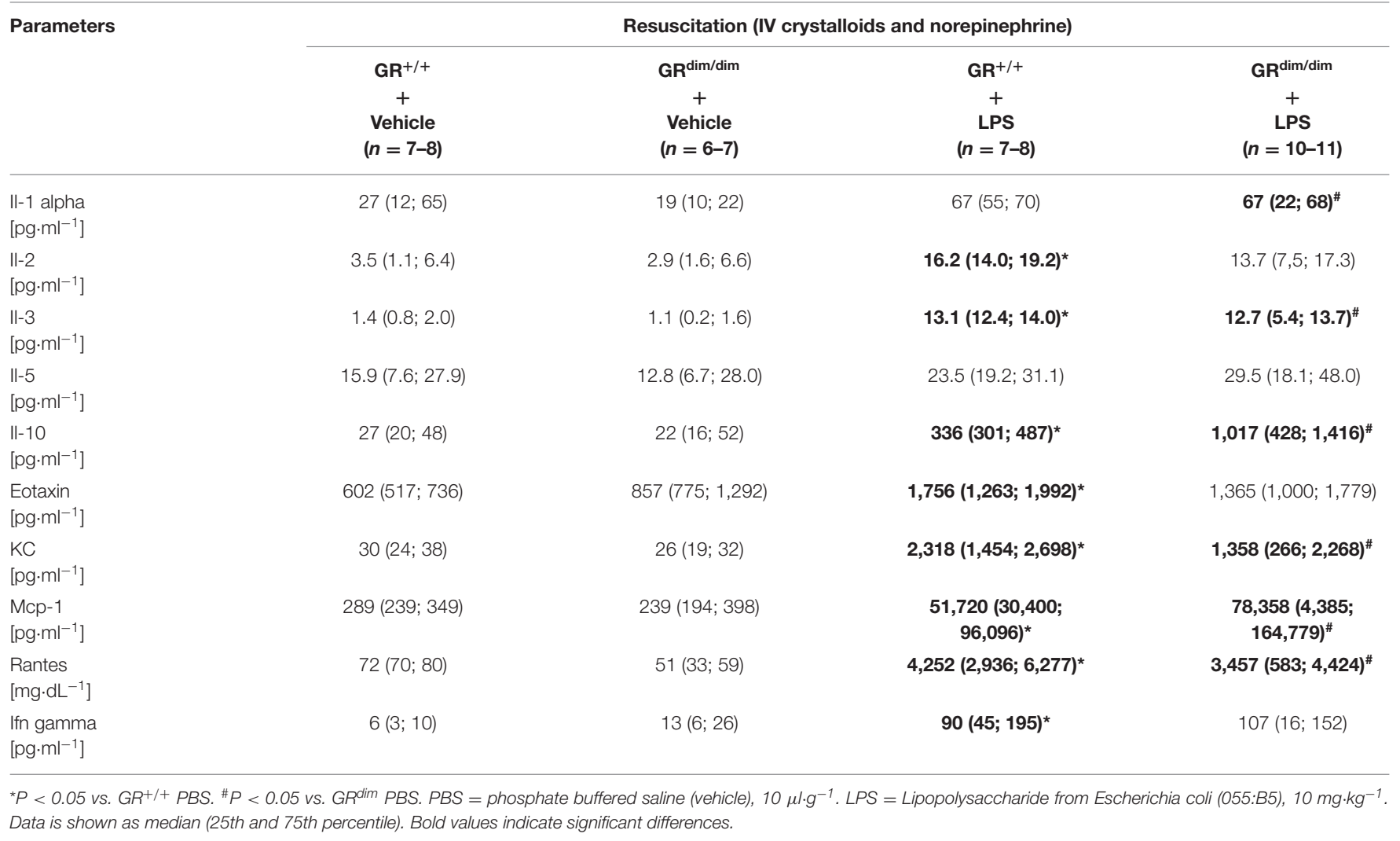

that correlated with lower albumin expression compared to $\mathrm{GR}^{\mathrm{dim} / \mathrm{dim}}$ challenged LPS mice having increased extravascular albumin expression and significantly reduced Sphk1 expression (Figures 4B,C). Taken together, lung function was impaired in $\mathrm{GR}^{\mathrm{dim} / \mathrm{dim}}$ mice upon LPS-challenge during intensive care treatment. In PBS-treated animals a so far not described slight basal difference in lung function was observed in $\mathrm{GR}^{\mathrm{dim} / \mathrm{dim}}$ mice. These data revealed that the dimerization of the GR is crucial for the lung compliance in an inflammatory setting under intensive care management.

\section{Increased Osteopontin in $\mathrm{GR}^{\mathrm{dim} / \mathrm{dim}}$ Mice Might Contribute to Disturbed Lung Function}

Inflammatory cytokine mRNA expression of $I l 1-\beta$ (Figure 5A), Il-6 (Figure 5B), Tnf $\alpha$ (Figure 5C), and Il-10 (Figure 5D) in the lung revealed no significant differences between $\mathrm{GR}^{\mathrm{dim} / \mathrm{dim}}$ and $\mathrm{GR}^{+/+}$mice after challenge with LPS under intensive care management. Therefore, the reduced lung compliance is most likely not a result of the aforementioned inflammatory mediators. Next to the expression of Sphk1, which was identified as an important regulator of lung barrier integrity, we now also aimed at other potential regulators of lung injury. Osteopontin (Opn, secreted phosphoprotein 1-Spp1) is a crucial mediator for inflammatory responses and a regulator of inflammation, especially lung inflammation. Opn neutralizing antibody could protect mice against ALI during sepsis (28). In our setting (intensive care management) Opn protein expression was significantly enhanced in lungs of $\mathrm{GR}^{\mathrm{dim} / \mathrm{dim}}$ compared to $\mathrm{GR}^{+/+}$mice, both under PBS-treatment and LPS-challenge (Figures 6A,B). Opn was shown to have an impact on type-1 immunity to bacterial infections as OPN deficient mice have increased Il-10 production (29). In accordance with this, $\mathrm{GR}^{\mathrm{dim} / \mathrm{dim}}$ mice with increased levels of Opn showed a trend toward reduced Il-10 mRNA expression in the lung compared to $\mathrm{GR}^{+/+}$mice during PBS and LPS-challenge (Figure 5D). This suggests that increased Opn expression in the lung of $\mathrm{GR}^{\mathrm{dim} / \mathrm{dim}}$ mice might have an impact on Il-10 mRNA expression. However, in the plasma of $\mathrm{GR}^{+/+}$and $\mathrm{GR}^{\mathrm{dim} / \mathrm{dim}}$ PBS- and LPS-challenged animals only a trend to induced Opn expression was observed, due to high variations in the groups (Supplementary Figure 2A). To assess the effect of impaired GR dimerization in macrophages and their contribution to Opn expression and inflammatory cytokines bone marrowderived macrophages (BMDM) from $\mathrm{GR}^{+/+}$and $\mathrm{GR}^{\operatorname{dim} / \mathrm{dim}}$ animals were stimulated with LPS. LPS stimulation increased the inflammatory cytokine expression in $\mathrm{GR}^{+/+}$and $\mathrm{GR}^{\mathrm{dim} / \mathrm{dim}}$ BMDMs, however, no genotype difference for the upregulation of Il-6 expression (Supplementary Figure 2B), Tnf $\alpha$ expression (Supplementary Figure 2C), and iNos expression (Supplementary Figure 2D) could be detected after LPS 

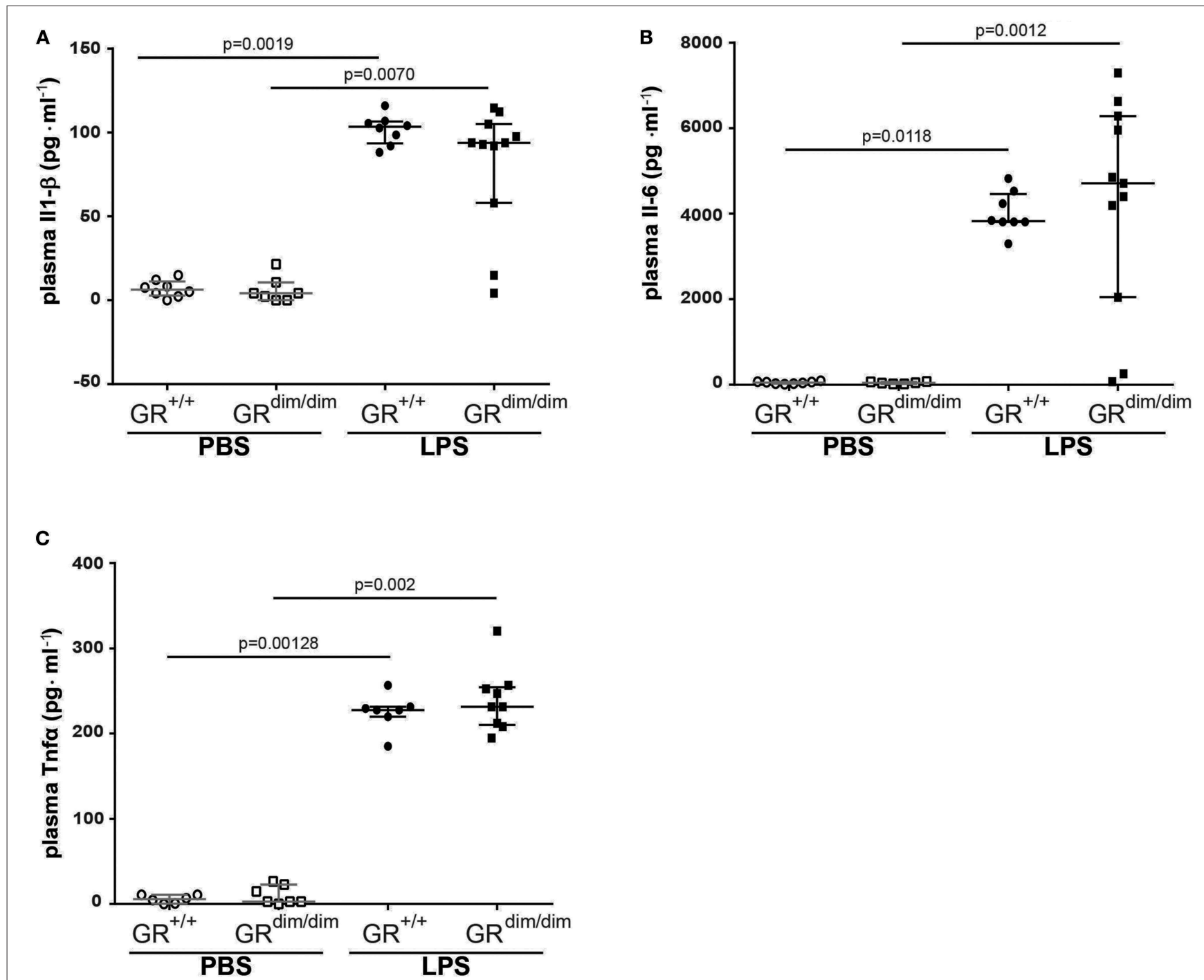

FIGURE 3 | Level of inflammatory cytokines in the plasma. Concentration of (A) interleukin 6 (II-6), (B) interleukin $1 \beta$ (II-1 $\beta$ ), and (C) tumor necrosis factor $\alpha$ (Tnfa) in the plasma of $\mathrm{GR}^{\mathrm{dim} / \mathrm{dim}}$ and $\mathrm{GR}^{+/+}$mice after an intraperitoneally challenge with lipopolysaccharides (LPS) or treatment with PBS. LPS $=$lipopolysaccharide from Escherichia coli [055:B5], $10 \mathrm{mg} \cdot \mathrm{kg}^{-1}$, dissolved in $10 \mu \mathrm{l} \cdot \mathrm{g}^{-1}$ phosphate buffered saline (PBS). GR $+/+$ mice challenged with PBS: $n=6-8$, GR dim/dim mice challenged with PBS: $n=6-7, \mathrm{GR}^{+/+}$mice challenged with LPS: $n=7-8$, GR dim/dim mice challenged with LPS: $n=9-11$. Data is presented as median (25th and 75th percentile and minimum/maximum).

treatment. Opn expression was not different, however a slight, but not significant, increase could be detected after LPS treatment in $\mathrm{GR}^{+/+}$and $\mathrm{GR}^{\mathrm{dim} / \mathrm{dim}}$ BMDMs with a more pronounced trend in the GR $\mathrm{dim}^{\mathrm{dim}}$ BMDMs (Supplementary Figure 2E). This observation is supported by the Opn levels in the supernatant of the LPS-treated GR ${ }^{\mathrm{dim} / \mathrm{dim}}$ BMDMs, that showed a trend to induced Opn compared to $\mathrm{GR}^{+/+}$, however, not significantly different (Supplementary Figure 2F). This suggests that macrophages are not the main source of $\mathrm{GR}^{\mathrm{dim} / \mathrm{dim}}$ dependent regulation of Opn, but they contribute to the Opn induction. Moreover, these data suggest that GR dimerization dependent regulation of Opn in vivo might depend on other cells.

In summary, there is possibly a correlation between increased Opn expression in the lung of the GR $\mathrm{dim}^{\mathrm{dim}}$ mice that renders them more sensitive during inflammation and therefore, Opn may be a target for the reduced lung compliance.

\section{DISCUSSION}

In the present study, we tested the hypothesis if an impaired glucocorticoid receptor (GR) function, presented as an impaired GR dimerization (GR ${ }^{\mathrm{dim}}$ ), would impair organ function in lipopolysaccharide (LPS)-induced systemic inflammation in mice undergoing intensive care treatment to compensate for LPSinduced cardiovascular depression. We found that $\mathrm{GR}^{\mathrm{dim} / \mathrm{dim}}$ mice challenged with LPS had a significantly increased need of norepinephrine to achieve hemodynamic targets and a more 

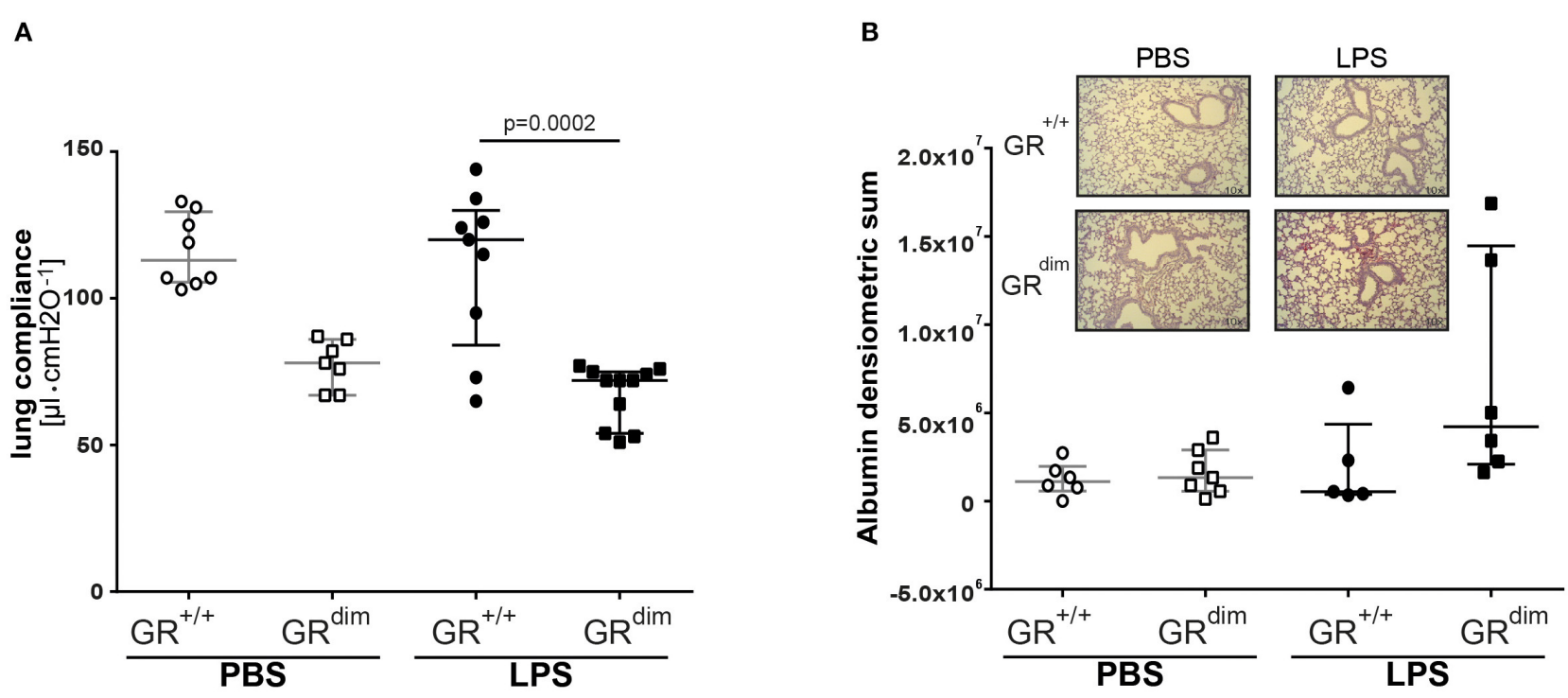

C

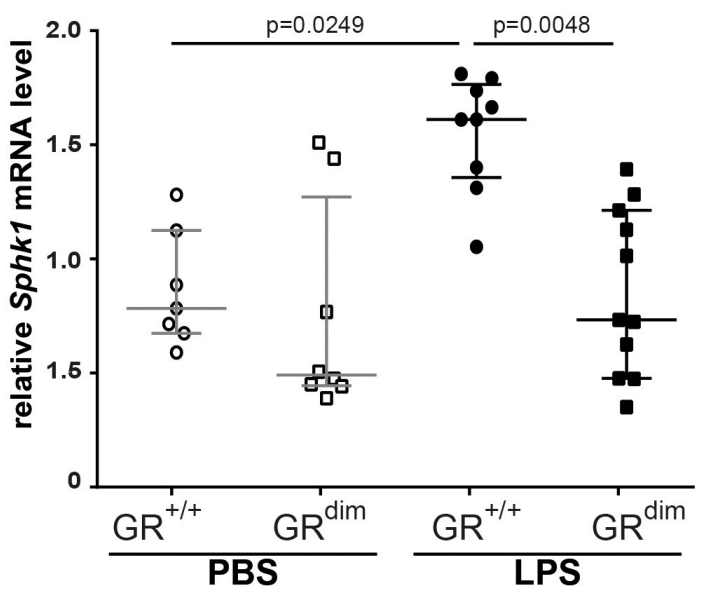

FIGURE 4 | Lung function and mRNA expression of glucocorticoid receptor associated genes in mechanically ventilated GR ${ }^{\text {dim/dim }}$ and $\mathrm{GR}^{+/+}$mice intraperitoneally challenged with lipopolysaccharides (LPS) or vehicle (PBS). (A) Lung compliance: $p=0.0735$ for $\mathrm{GR}^{+/+}$vs. GR ${ }^{\text {dim/dim }}$ mice treated with PBS for Kruskal-Wallis-Test with multiple comparisons and post-hoc Dunn's Test. LPS = lipopolysaccharide from Escherichia coli [055:B5], $10 \mathrm{mg} \cdot \mathrm{kg}^{-1}$, dissolved in $10 \mu \mathrm{l} \cdot \mathrm{g}^{-1} \mathrm{phosphate}$ buffered saline (PBS). GR ${ }^{+/+}$mice challenged with PBS: $n=8$, GR dim/dim mice challenged with PBS: $n=7, \mathrm{GR}^{+/+}$mice challenged with LPS: $n=9$, GR dim/dim mice challenged with LPS: $n=11$. Data is presented as median (25th and 75th percentile and minimum/maximum). (B) Immunohistochemical (IHC) analysis of extravascular albumin expression in lung tissue of $\mathrm{GR}^{\mathrm{dim} / \mathrm{dim}}$ and $\mathrm{GR}^{+/+}$mice challenged with lipopolysaccharide (LPS) or vehicle (PBS) and example pictures of albumin extravasation in lung tissue in $\mathrm{GR}^{+/+}$and $\mathrm{GR}^{\mathrm{dim} / \mathrm{dim}}$ mice (lower picture). Albumin was detected with a secondary Alkaline Phosphatase-conjugated antibody and visualized with a red chromogen and regions were quantified for signal. GR ${ }^{+/+}$mice challenged with PBS: $n=6$, GR dim/dim mice challenged with PBS: $n=7$, $\mathrm{GR}^{+/+}$mice challenged with LPS: $n=5$, GR ${ }^{\text {dim/dim }}$ mice challenged with LPS: $n=6$. Data is presented as median (25th and 75 th percentile and minimum/maximum). (C) Measurements of relative mRNA level of sphingosine kinase 1 (Sphk1) in lung tissue of GR ${ }^{\text {dim/dim }}$ and $\mathrm{GR}^{+/+}$mice challenged with lipopolysaccharide (LPS) or vehicle (PBS). GR ${ }^{+/+}$mice challenged with PBS: $n=7$, GR dim/dim mice challenged with PBS: $n=8, \mathrm{GR}^{+/+}$mice challenged with LPS: $n=9$, GR dim/dim mice challenged with LPS: $n=11$. Data is presented as median (25th and 75 th percentile and minimum/maximum).

pronounced lactic acidosis during resuscitation measures ("lungprotective" ventilation, fluid resuscitation, and norepinephrine treatment) compared to LPS-challenged $\mathrm{GR}^{+/+}$mice. Most interestingly, GR ${ }^{\mathrm{dim} / \mathrm{dim}}$ mice challenged with LPS presented with aggravated ALI, shown by a more pronounced impairment of lung mechanics when compared to LPS-challenged $\mathrm{GR}^{+/+}$ mice. According to the results of the present study, the impaired lung function in $\mathrm{GR}^{\mathrm{dim} / \mathrm{dim}}$ mice was most likely mediated via an increased endothelial barrier dysfunction, indicated via a reduced expression of sphingosine kinase 1 (Sphk1), which was associated with a higher albumin extravasation in lung tissue. Furthermore, the lung injury in $\mathrm{GR}^{\mathrm{dim} / \mathrm{dim}}$ mice was accompanied by an increase in Osteopontin (Opn) levels in lung tissue, which indicated Opn as a marker of lung injury. The impaired lung 
TABLE 4 | Quantification of lung histology analysis in $\mathrm{GR}^{\mathrm{dim} / \mathrm{dim}}$ and $\mathrm{GR}^{+/+}$mice that underwent an intraperitoneally challenge with lipopolysaccharide (LPS) or vehicle (phosphate buffered saline, PBS) and were resuscitated for $6 \mathrm{~h}$ thereafter.

\begin{tabular}{|c|c|c|c|c|}
\hline \multirow[t]{2}{*}{ Parameters } & \multicolumn{4}{|c|}{ Resuscitation (IV crystalloids and norepinephrine) } \\
\hline & $\begin{array}{c}\mathrm{GR}^{+/+} \\
+ \\
\text {Vehicle } \\
(n=8)\end{array}$ & $\begin{array}{c}\text { GR }^{\mathrm{dim} / \mathrm{dim}} \\
+ \\
\text { Vehicle } \\
(n=7)\end{array}$ & $\begin{array}{c}\mathrm{GR}^{+/+} \\
+ \\
\text {LPS } \\
(n=5)\end{array}$ & $\begin{array}{c}\text { GR }^{\operatorname{dim} / \operatorname{dim}} \\
+ \\
\text { LPS } \\
(n=6)\end{array}$ \\
\hline $\begin{array}{l}\text { Alveolar } \\
\text { membrane } \\
\text { thickening }\end{array}$ & $1.0(0.9 ; 1.0)$ & $1.5(1.0 ; 2.0)$ & $1.0(1.0 ; 2.0)$ & $1.5(1.0 ; 2.0)$ \\
\hline Dystelectasis & $0.5(0.0 ; 0.5)$ & $0.5(0.0 ; 1.0)$ & $0.0(0.0 ; 0.0)$ & $0.3(0.0 ; 0.5)$ \\
\hline Emphysema & $2.0(2.0 ; 2.0)$ & $2.0(1.8 ; 2.0)$ & $2.5(2.5 ; 2.5)$ & $2.5(2.0 ; 3.0)$ \\
\hline Lymphocytes & $1.0(1.0 ; 1.3)$ & $2.0(2.0 ; 2.5)^{\star}$ & $1.0(1.0 ; 2.0)$ & $2.0(1.3 ; 2.0)$ \\
\hline tal s & $4.5(4.0 ; 5.0)$ & $6.0(5.8 ; 7.0)$ & $4.5(4.5 ; 6.5)$ & $5.8(5.1 ; 6.8)$ \\
\hline
\end{tabular}

For detailed description of the score for histological tissue analysis see Methods section. ${ }^{\star} P<0.05$ vs. $G R^{+/+}$vehicle. PBS = phosphate buffered saline (vehicle), $L P S=$ Lipopolysaccharide from Escherichia coli (055:B5), $10 \mathrm{mg} \mathrm{kg}^{-1}$. Data is shown as median (interquartile range).

function in $\mathrm{GR}^{\mathrm{dim}} / \mathrm{dim}$ mice after LPS-challenge was not mediated via the systemic inflammatory response, because we found no differences in cytokine levels between the genotypes, neither in lung tissue (Figure 3) nor in plasma (Table 3).

We previously showed that $\mathrm{GR}^{\mathrm{dim} / \mathrm{dim}}$ mice present a higher mortality in LPS-and cecal ligation and puncture (CLP)-induced systemic inflammation without any resuscitation procedures (18). In the present study, after LPS-challenge $\mathrm{GR}^{\mathrm{dim} / \mathrm{dim}}$ mice had (i) an increased hemodynamic instability indicated by a significantly increased need of norepinephrine, (ii) more pronounced lactic acidosis, and (iii) a reduced lung compliance, which altogether lead to an increased mortality rate despite resuscitative measures. The increased mortality of $\mathrm{GR}^{\mathrm{dim} / \mathrm{dim}}$ mice in the current study (Supplementary Figure 1) confirms that the GR dimer is of importance for survival after challenge with LPS, even when animals receive fluid resuscitation and norepinephrine treatment to achieve target hemodynamics as well as "lung-protective" mechanical ventilation $(22,23)$.

i) Hemodynamic instability: In the present study, GR $\mathrm{dim} / \mathrm{dim}$ mice presented with an aggravated hemodynamic instability after LPS-challenge, reflected by a significantly increased need of norepinephrine to reach hemodynamic targets (Figure 1). Aggravated hemodynamic instability after LPSchallenge, which also led to increased mortality, has also been reported in mice with an endothelial-specific GR deletion $\left(\mathrm{GR}^{\mathrm{ECKO}}\right)$ (30). The increased hemodynamic instability in these mice was accompanied by an increased expression of inducible (iNOS) and endothelial (eNOS) nitric oxide synthase (NOS), which resulted in increased levels of nitric oxide (NO) following LPS-challenge, thus contributing to arterial hypotension. Interestingly, corticosterone levels increased after challenge with LPS, but did not differ between $\mathrm{GR}^{\mathrm{ECKO}}$ and control mice (30). While an endothelial GR dysfunction induces hypotension, in other studies it is reported that a stimulation of an intact GR via GCs leads to hypertension. In addition, this GC-induced hypertension was reported to be mediated via downregulation of eNOS in rats (31). Therefore, endothelial GR dysfunction leads to NO-induced hypotension, whereas GR stimulation via GCs leads to downregulation of NO synthases, which induces hypertension. Although we did not examine any vascular specific effects of an ubiquitous impairment of GR dimerization, it is likely that the increased hemodynamic instability in $\mathrm{GR}^{\mathrm{dim} / \mathrm{dim}}$ mice has been, at least in part, meditated via a NO-induced vasodilation after LPSchallenge in the present study as reported previously (30). The anesthesia and surgery represent a trauma for the animals and this is most likely the reason for the slight increased mortality of the $\mathrm{GR}^{\mathrm{dim} / \mathrm{dim}}$ mice compared to $\mathrm{GR}^{+/+}$challenged with PBS. We can only speculate about the reasons for this increased instability. Due to the decreased blood pressure in the $\mathrm{GR}^{\mathrm{dim} / \mathrm{dim}}$ mice during the ICU management, it is most likely that either the systemic vascular resistance or the cardiac output is affected. A decreased hemodynamic instability has already been described for mice with an endothelial glucocorticoid receptor knockout (30).

ii) Lactic acidosis: Additionally, GR $\mathrm{R}^{\mathrm{dim} / \mathrm{dim}}$ mice developed lactic acidosis until the end of the LPS-challenge (Table 2). In the present study, $\mathrm{GR}^{+/+}$mice showed an increase in mitochondrial respiration in the liver, which was lacking in $\mathrm{GR}^{\mathrm{dim} / \mathrm{dim}}$ mice (Figure 2). Moreover, GR ${ }^{\mathrm{dim} / \mathrm{dim}}$ mice presented with a more severe shock and lactic acidosis under highest norepinephrine requirements to counteract arterial hypotension. While shock-induced hypotension causes increased norepinephrine needs to achieve hemodynamic targets, shock-related lactic acidosis originates from disturbed microcirculatory perfusion and/or impaired cellular $\mathrm{O}_{2}$ utilization, the later possibly resulting from mitochondrial dysfunction. Moreover, catecholamines per se can aggravate both, impaired microcirculatory perfusion and mitochondrial dysfunction, the latter as a result of increased radical formation. Therefore, the lacking increase in mitochondrial respiration in LPS-challenged GR ${ }^{\mathrm{dim} / \mathrm{dim}}$ mice in the liver and the more pronounced lactic acidosis might be explained by a mitochondrial dysfunction per se and/or due to higher norepinephrine doses.

iii) Lung compliance: The importance of the GR for lung function already becomes apparent during lung maturation in utero. Here, GR signaling mediates downsizing of the interstitial mesenchymal tissue compartment. This in turn brings the underlying vasculature into close proximity with the future alveolar airspaces, and enables oxygenation of the blood, therefore allowing survival after birth ex utero (32). The importance of the GR for survival after birth becomes apparent even more when studying GR deficient mice. At birth, these $\mathrm{GR}^{-/-}$mice die within a few hours due to respiratory distress, which seems to be mediated through severe lung atelectasis (33). Interestingly, in these $\mathrm{GR}^{-/-}$mice, severe lung atelectasis could not be linked to an impaired surfactant homeostasis. In the present study, we studied mice with 
A

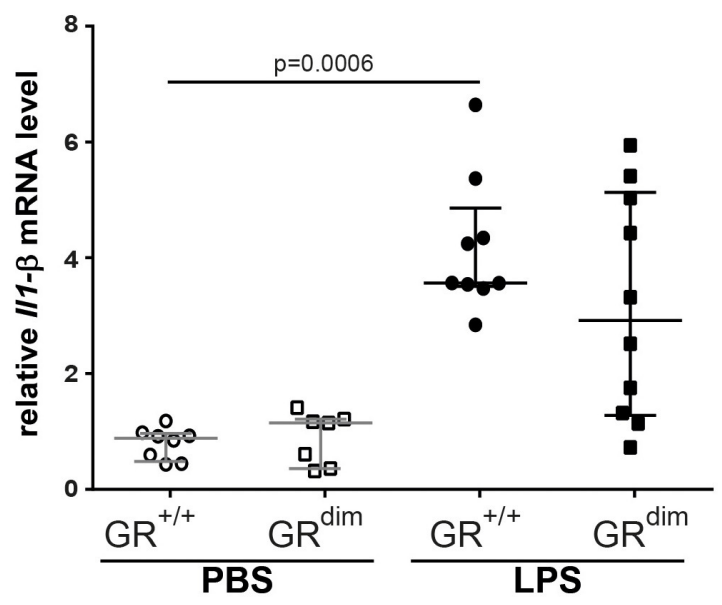

C

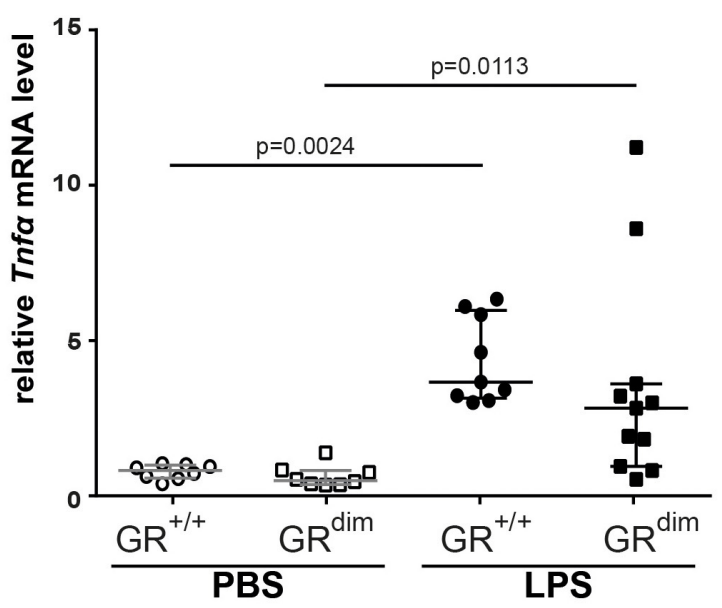

B

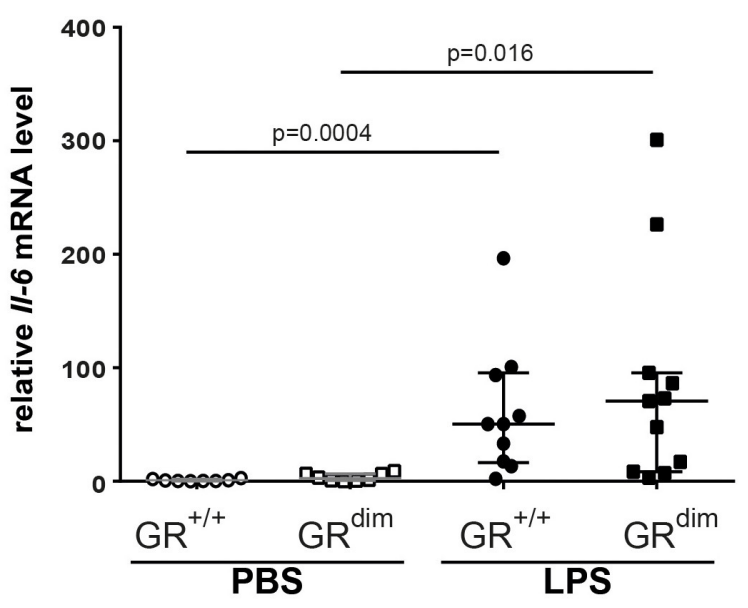

D

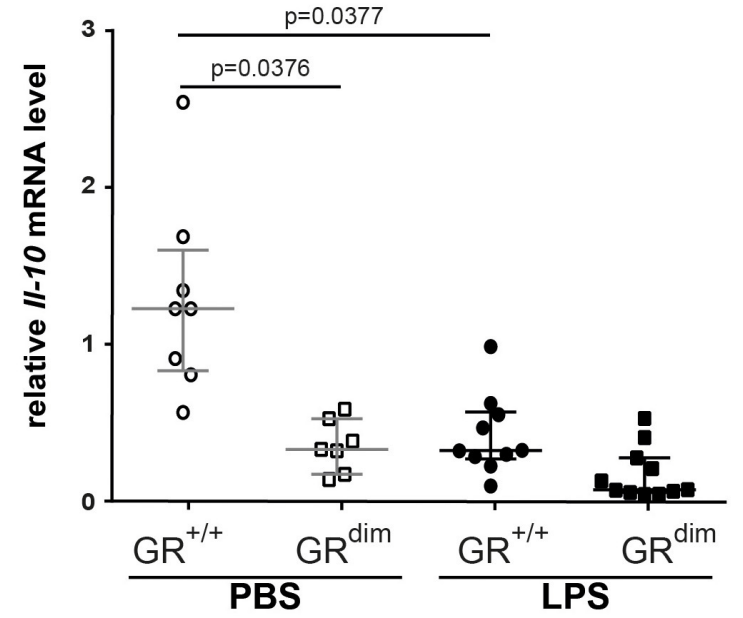

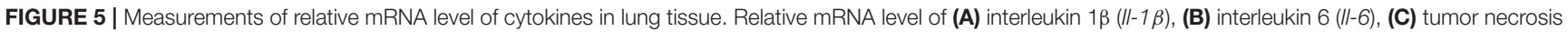
factor $\alpha\left(\right.$ Tnf $\alpha$ ), and (D) interleukin 10 (II-10) in lung tissue of $\mathrm{GR}^{\text {dim/dim }}$ and $\mathrm{GR}^{+/+}$mice intraperitoneally challenged with lipopolysaccharide (LPS) or vehicle (PBS). LPS = lipopolysaccharide from Escherichia coli [055:B5], $10 \mathrm{mg} \cdot \mathrm{kg}^{-1}$, dissolved in $10 \mu \mathrm{l} \cdot \mathrm{g}^{-1}$ phosphate buffered saline (PBS). GR ${ }^{+/+}$mice challenged with PBS: $n=$ 8, GR ${ }^{\mathrm{dim} / \mathrm{dim}}$ mice challenged with PBS: $n=7-8, \mathrm{GR}^{+/+}$mice challenged with LPS: $n=9-10$, GR ${ }^{\mathrm{dim} / \mathrm{dim}}$ mice challenged with LPS: $n=10-11$. Data is presented as median (25th and 75th percentile and minimum/maximum).

an attenuated GR dimerization $\left(\mathrm{GR}^{\mathrm{dim} / \mathrm{dim}}\right)$, which leads to only partial GR impairment; therefore these mice survive after birth. However, in our model of systemic inflammation via LPS-challenge, GR ${ }^{\mathrm{dim} / \mathrm{dim}}$ mice presented with impaired lung function, here indicated by a reduced lung compliance (Figure 4A). This reduced lung compliance was accompanied by a clear trend toward an increased albumin extravasation in $\mathrm{GR}^{\mathrm{dim} / \mathrm{dim}}$ mice after LPSchallenge (Figure 4B), indicating an impaired lung barrier function. Independent of the presence or absence of ICU treatment, we (13) and others (34-36) reported an impaired lung barrier function after LPS-challenge in previous studies. A major mediator of endothelial barrier function in the lung is sphingosine kinase 1 (SphK1). The impaired lung barrier function in our previous study could be linked to a
GR dimerization-dependent SphK1 expression in myeloid cells, particularly macrophages, because ablation of the SphK1 gene in the myeloid lineage abolished GC effects on vascular leakage and inflammation (13). In addition, mice with a complete deletion of SphK1 (SphK1-/-) are highly susceptible to LPS-induced ALI and exhibit increased lung vascular leakage (37). In the current study, reduced lung compliance after LPS-challenge was accompanied by a significantly lower Sphk1 expression in $\mathrm{GR}^{\mathrm{dim} / \mathrm{dim}}$ mice (Figure 4C), highlighting the contribution of Sphk1 expression to mediate a physiological lung function. In addition, there was no change in lung compliance in $\mathrm{GR}^{+/+}$ mice despite LPS-challenge but a significant increase of lung Sphk1 expression compared to PBS-treated $\mathrm{GR}^{+/+}$mice, which also might suggest a beneficial impact of SphK1 

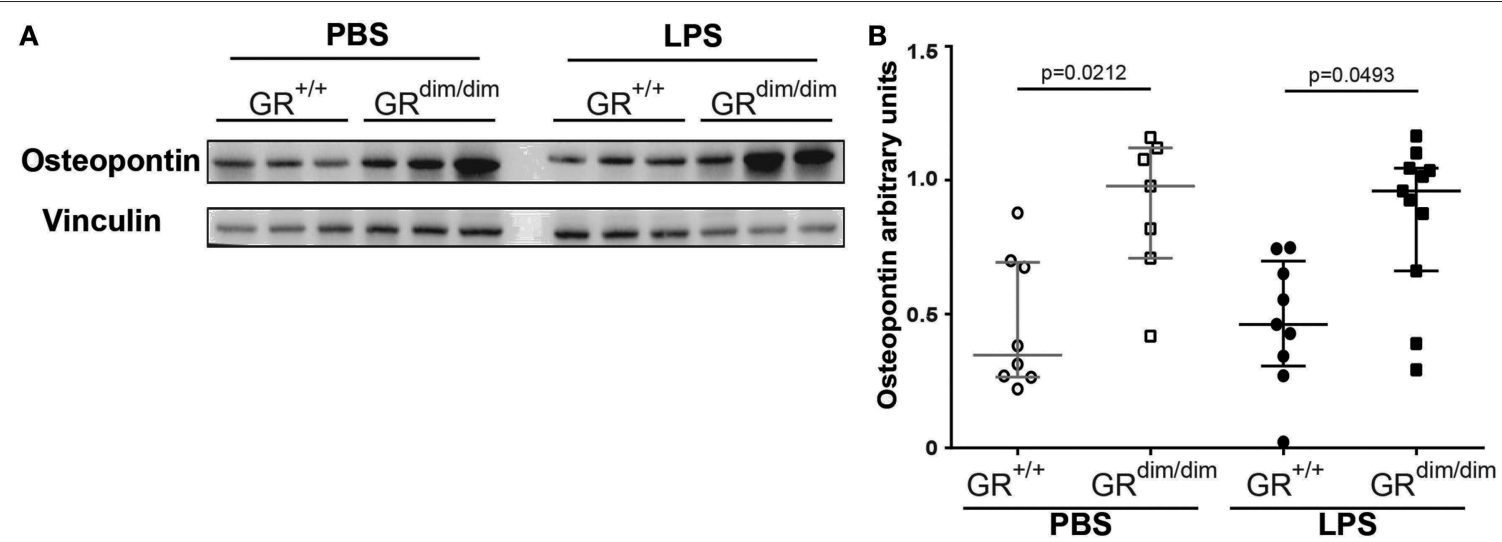

FIGURE 6 | Analysis of Osteopontin (Opn) levels in lung tissue. (A) Representative western blot analysis and (B) arbitrary units of Opn, in lung tissue of GRdim/dim and $\mathrm{GR}^{+/+}$mice intraperitoneally challenged with lipopolysaccharide (LPS) or vehicle (PBS). LPS = lipopolysaccharide from Escherichia coli [055:B5], 10 mg.kg ${ }^{-1}$, dissolved in $10 \mu \mathrm{l} \cdot \mathrm{g}^{-1}$ phosphate buffered saline (PBS). GR ${ }^{+/+}$mice challenged with PBS: $n=8$, GR ${ }^{\text {dim/dim mice challenged with PBS: } n=7 \text {, GR }}$ (/+ mice challenged with LPS: $n=9$, GR dim/dim mice challenged with LPS: $n=11$. Data is presented as median (25th and 75 th percentile and minimum/maximum).

in lung function. However, PBS-treated $\mathrm{GR}^{\mathrm{dim} / \mathrm{dim}}$ mice revealed a trend toward a reduced lung Sphk1 expression, which correlates with the trend, however, not significant, to reduced lung compliance in $\mathrm{GR}^{\mathrm{dim} / \mathrm{dim}}$ animals.

The glucocorticoid receptor is involved in modulating the host response to inflammatory stimuli; therefore, we assessed cytokine mRNA levels in lung tissue (Figure 5) as well as cytokine concentrations in the plasma (Figure 3 and Table 3). Interestingly, we did not find any significant genotype difference in systemic inflammatory mediators in the plasma and lung mRNA expression after LPS-challenge. However, in our previous LPS-induced endotoxic shock model without intensive care management we already described that $\mathrm{GR}^{\mathrm{dim} / \mathrm{dim}}$ mice present increased levels of inflammatory mediators at later time points (18). This could explain the difference to our present findings, where mice were observed for only $6 \mathrm{~h}$ after LPS-induced endotoxic shock under intensive care management.

Another inflammatory mediator involved in the pathogenesis of inflammatory diseases is osteopontin (Opn) $(38,39)$, especially in the lung, as patients with various pulmonary diseases revealed increased lung Opn expression (40-45). Furthermore, in experimental models of lung diseases (asthma, lung injury, lung fibrosis), Opn has a detrimental and functional role (40, 4650 ), and, moreover, Opn neutralizing antibody could protect mice against ALI during sepsis (28). We showed that mice with an impaired GR dimerization have elevated Opn protein expression in the lung, the same animals that had a significant decrease in lung compliance after LPS-induced endotoxic shock. The finding that Opn might be a critical regulator of lung compliance is supported by Opn knockout mice showing an increased lung compliance (51). Here we describe, for the first time, that Opn expression in the lung is linked with GR dimerization. Mice lacking GR dimerization had increased Opn expression in the lung, which was accompanied by impaired lung mechanics.
Il-10 is described to be negatively regulated by Opn in LPS-stimulated macrophages, higher Il-10 levels were observed during infections in Opn knockout mice (29). Our data showed a trend to reduced $\mathrm{Il}-10$ expression in the lung of PBS-treated $\mathrm{GR}^{\mathrm{dim} / \mathrm{dim}}$ mice (Figure 5), and this effect was enhanced in the inflammatory setting. In addition, $\mathrm{GR}^{+/+}$animals revealed a trend to reduced $\mathrm{Il}-10$ expression in the lung upon inflammation, independent of Opn, suggesting an alternative regulation of $\mathrm{Il-10}$ that might be mis-regulated in GR ${ }^{\mathrm{dim} / \mathrm{dim}}$ animals. Possibly, the duration of the $\mathrm{GR}^{\mathrm{dim} / \mathrm{dim}}$ mice in the intensive care management during systemic inflammation was too short to detect more pronounced effects concerning inflammatory cytokines, because our previous results during systemic inflammation (without intensive care management) revealed significant differences at later time points only (18).

In conclusion, impairment of GR dimerization aggravates systemic hypotension and impairs lung function during LPSinduced endotoxic shock in mice. We now demonstrate that the GR dimer is an important mediator of hemodynamic stability and lung function during LPS-induced systemic inflammation. Further studies are warranted to examine if selective activation of the GR dimer may be able to attenuate lung injury during systemic inflammation.

\section{DATA AVAILABILITY STATEMENT}

All datasets generated for this study are included in the article/Supplementary Material.

\section{ETHICS STATEMENT}

The animal study was reviewed and approved by the federal authorities for animal research of the Regierungspräsidium Tübingen, Baden-Wuerttemberg, Germany. 


\section{AUTHOR CONTRIBUTIONS}

SV, MW, EC, PR, and JT conceived and designed the study. SV, MW, JP, TM, CH, UW, OM, JV, SK, MG, MF, EC, and UB performed the experiments and organ analysis. AS and PM examined the histology. SV, MW, JP, TM, UW, and OM analyzed the data and interpreted the results. SV, JP, and MW prepared the figures. SV and MW wrote the manuscript. PR and JT revised the manuscript.

\section{FUNDING}

PR and JT were supported by the Deutsche Forschungsgemeinschaft (Collaborative Research Center 1149, DFG Tu 220/13-1 to JT). MW was supported by the GEROK program of the Deutsche Forschungsgemeinschaft (Collaborative Research Center 1149), and the University Hospital Ulm. CH

\section{REFERENCES}

1. Lim H-W, Uhlenhaut NH, Rauch A, Weiner J, Hübner S, Hübner N, et al. Genomic redistribution of GR monomers and dimers mediates transcriptional response to exogenous glucocorticoid in vivo. Genome Res. (2015) 25:836-44. doi: $10.1101 /$ gr.188581.114

2. Reichardt HM, Tuckermann JP, Göttlicher M, Vujic M, Weih F, Angel $\mathrm{P}$, et al. Repression of inflammatory responses in the absence of DNA binding by the glucocorticoid receptor. EMBO J. (2001) 20:7168-73. doi: $10.1093 / \mathrm{emboj} / 20.24 .7168$

3. Tuckermann JP, Reichardt HM, Arribas R, Richter KH, Schütz G, Angel P. The DNA binding-independent function of the glucocorticoid receptor mediates repression of AP-1-dependent genes in skin. J Cell Biol. (1999) 147:1365-70. doi: $10.1083 /$ jcb.147.7.1365

4. de Bosscher K, Schmitz ML, Vanden Berghe W, Plaisance S, Fiers W, Haegeman G. Glucocorticoid-mediated repression of nuclear factor- $\mathrm{B}$ dependent transcription involves direct interference with transactivation. Proc Natl Acad Sci USA. (1997) 94:13504-9. doi: 10.1073/pnas.94.25.13504

5. Heck S, Bender K, Kullmann M, Göttlicher M, Herrlich P, Cato AC. IкB $\alpha-$ independent downregulation of $\mathrm{NF}-\kappa \mathrm{B}$ activity by glucocorticoid receptor. EMBO J. (1997) 16:4698-707. doi: 10.1093/emboj/16.15.4698

6. Jonat C, Rahmsdorf HJ, Park KK, Cato AC, Gebel S, Ponta H, et al. Antitumor promotion and antiinflammation: down-modulation of AP-1 (Fos/Jun) activity by glucocorticoid hormone. Cell. (1990) 62:1189-204. doi: 10.1016/0092-8674(90)90395-U

7. Yang-Yen HF, Chambard JC, Sun YL, Smeal T, Schmidt TJ, Drouin J, et al. Transcriptional interference between c-Jun and the glucocorticoid receptor: mutual inhibition of DNA binding due to direct proteinprotein interaction. Cell. (1990) 62:1205-15. doi: 10.1016/0092-8674(90) 90396-V

8. Schüle R, Rangarajan P, Kliewer S, Ransone LJ, Bolado J, Yang N, et al. Functional antagonism between oncoprotein c-Jun and the glucocorticoid receptor. Cell. (1990) 62:1217-26. doi: 10.1016/0092-8674(90)90397-W

9. Ogawa S, Lozach J, Benner C, Pascual G, Tangirala RK, Westin S, et al. Molecular determinants of crosstalk between nuclear receptors and toll-like receptors. Cell. (2005) 122:707-21. doi: 10.1016/j.cell.2005.06.029

10. Reily MM, Pantoja C, Hu X, Chinenov Y, Rogatsky I. The GRIP1:IRF3 interaction as a target for glucocorticoid receptormediated immunosuppression. EMBO J. (2006) 25:108-17. doi: 10.1038/sj.emboj.7600919

11. Flammer JR, Dobrovolna J, Kennedy MA, Chinenov Y, Glass CK, Ivashkiv LB, et al. The type I interferon signaling pathway is a target for glucocorticoid inhibition. Mol Cell Biol. (2010) 30:4564-74. doi: 10.1128/MCB.00146-10 was supported by the Hertha-Nathorff-Fellowship of the Medical Faculty of Ulm University. SV was supported by the Deutsche Forschungsgemeinschaft (Collaborative Research Center 1149), Pulmosens GRK 2203, and the University Hospital Ulm.

\section{ACKNOWLEDGMENTS}

We are grateful to the staff of the animal facilities of the University of Ulm, our animal welfare officer Dr. Sibylle Ott and in particular to Birgit Widmann.

\section{SUPPLEMENTARY MATERIAL}

The Supplementary Material for this article can be found online at: https://www.frontiersin.org/articles/10.3389/fimmu. 2019.03152/full\#supplementary-material

12. Hübner S, Dejager L, Libert C, Tuckermann JP. The glucocorticoid receptor in inflammatory processes: transrepression is not enough. Biol Chem. (2015) 396:1223-31. doi: 10.1515/hsz-2015-0106

13. Vettorazzi S, Bode C, Dejager L, Frappart L, Shelest E, Klaßen C, et al. Glucocorticoids limit acute lung inflammation in concert with inflammatory stimuli by induction of SphK1. Nat Commun. (2015) 6:7796. doi: $10.1038 /$ ncomms 8796

14. Frijters R, Fleuren W, Toonen, Erik J M, Tuckermann JP, Reichardt HM, et al. Prednisolone-induced differential gene expression in mouse liver carrying wild type or a dimerization-defective glucocorticoid receptor. BMC Genomics. (2010) 11:359. doi: 10.1186/1471-2164-11-359

15. Tuckermann JP, Kleiman A, Moriggl R, Spanbroek R, Neumann A, Illing A, et al. Macrophages and neutrophils are the targets for immune suppression by glucocorticoids in contact allergy. J Clin Invest. (2007) 117:1381-90. doi: 10.1172/JCI28034

16. Baschant U, Frappart L, Rauchhaus U, Bruns L, Reichardt HM, Kamradt T, et al. Glucocorticoid therapy of antigen-induced arthritis depends on the dimerized glucocorticoid receptor in $\mathrm{T}$ cells. Proc Natl Acad Sci USA. (2011) 108:19317-22. doi: 10.1073/pnas.11058 57108

17. Vandevyver S, Dejager L, van Bogaert T, Kleyman A, Liu Y, Tuckermann J, et al. Glucocorticoid receptor dimerization induces MKP1 to protect against TNF-induced inflammation. J Clin Invest. (2012) 122:2130-40. doi: 10.1172/JCI60006

18. Kleiman A, Hübner S, Rodriguez Parkitna JM, Neumann A, Hofer S, Weigand $\mathrm{MA}$, et al. Glucocorticoid receptor dimerization is required for survival in septic shock via suppression of interleukin-1 in macrophages. FASEB J. (2012) 26:722-9. doi: 10.1096/fj.11-192112

19. Blé F-X, Cannet C, Zurbruegg S, Gérard C, Frossard N, Beckmann $\mathrm{N}$, et al. Activation of the lung $\mathrm{S} 1 \mathrm{P}(1)$ receptor reduces allergeninduced plasma leakage in mice. Br J Pharmacol. (2009) 158:1295-301. doi: 10.1111/j.1476-5381.2009.00391.x

20. Zhao Y, Gorshkova IA, Berdyshev E, He D, Fu P, Ma W, et al. Protection of LPS-induced murine acute lung injury by sphingosine-1phosphate lyase suppression. Am J Respir Cell Mol Biol. (2011) 45:426-35. doi: 10.1165/rcmb.2010-0422OC

21. Reichardt HM, Kaestner KH, Tuckermann J, Kretz O, Wessely O, Bock R, et al. DNA binding of the glucocorticoid receptor is not essential for survival. Cell. (1998) 93:531-41. doi: 10.1016/S0092-8674(00)81183-6

22. Gröger M, Wepler M, Wachter U, Merz T, McCook O, Kress S, et al. The effects of genetic 3-mercaptopyruvate sulfurtransferase deficiency in murine traumatic-hemorrhagic shock. Shock. (2019) 51:472-8. doi: 10.1097/SHK.0000000000001165 
23. Hartmann C, Gröger M, Noirhomme J-P, Scheuerle A, Möller P, Wachter U, et al. In-depth characterization of the effects of cigarette smoke exposure on the acute trauma response and hemorrhage in mice. Shock. (2018) 51:68-77. doi: 10.1097/SHK.0000000000001115

24. Wagner K, Gröger M, McCook O, Scheuerle A, Asfar P, Stahl B, et al. Blunt chest trauma in mice after cigarette smoke-exposure: effects of mechanical ventilation with $100 \% \mathrm{O}_{2}$. PLoS ONE. (2015) 107:e0132810. doi: 10.1371/journal.pone.0132810

25. Wagner F, Scheuerle A, Weber S, Stahl B, McCook O, Knöferl MW, et al. Cardiopulmonary, histologic, and inflammatory effects of intravenous Na2S after blunt chest trauma-induced lung contusion in mice. J Trauma. (2011) 71:1659-67. doi: 10.1097/TA.0b013e318228842e

26. Barth E, Albuszies G, Baumgart K, Matejovic M, Wachter U, Vogt J, et al. Glucose metabolism and catecholamines. Crit Care Med. (2007) 35(9 Suppl.):S508-18. doi: 10.1097/01.CCM.0000278047.06965.20

27. Vogt JA, Wachter U, Wagner K, Calzia E, Gröger M, Weber S, et al. Effects of glycemic control on glucose utilization and mitochondrial respiration during resuscitated murine septic shock. Intensive Care Med Exp. (2014) 21:19. doi: 10.1186/2197-425X-2-19

28. Hirano Y, Aziz M, Yang W-L, Wang Z, Zhou M, Ochani M, et al. Neutralization of osteopontin attenuates neutrophil migration in sepsis-induced acute lung injury. Crit Care. (2015) 19:53. doi: 10.1186/s13054-015-0782-3

29. Ashkar S, Weber GF, Panoutsakopoulou V, Sanchirico ME, Jansson M, Zawaideh S, et al. Eta-1 (osteopontin): an early component of type-1 (cell-mediated) immunity. Science. (2000) 287:860-4. doi: 10.1126/science.287.5454.860

30. Goodwin JE, Feng Y, Velazquez H, Sessa WC. Endothelial glucocorticoid receptor is required for protection against sepsis. Proc Natl Acad Sci USA. (2013) 110:306-11. doi: 10.1073/pnas.1210200110

31. Wallerath T, Witte K, Schäfer SC, Schwarz PM, Prellwitz W, Wohlfart P, et al. Down-regulation of the expression of endothelial NO synthase is likely to contribute to glucocorticoid-mediated hypertension. Proc Natl Acad Sci USA. (1999) 96:13357-62. doi: 10.1073/pnas.96.23.13357

32. Bird AD, McDougall ARA, Seow B, Hooper SB, Cole TJ. Glucocorticoid regulation of lung development: lessons learned from conditional GR knockout mice. Mol Endocrinol. (2015) 29:158-71. doi: 10.1210/me.20141362

33. Cole TJ, Blendy JA, Monaghan AP, Krieglstein K, Schmid W, Aguzzi A, et al. Targeted disruption of the glucocorticoid receptor gene blocks adrenergic chromaffin cell development and severely retards lung maturation. Genes Dev. (1995) 9:1608-21. doi: 10.1101/gad.9.13.1608

34. Kreil EA, Greene E, Fitzgibbon C, Robinson DR, Zapol WM. Effects of recombinant human tumor necrosis factor alpha, lymphotoxin, and Escherichia coli lipopolysaccharide on hemodynamics, lung microvascular permeability, and eicosanoid synthesis in anesthetized sheep. Circ Res. (1989) 65:502-14. doi: 10.1161/01.RES.65.2.502

35. Petersen B, Bloch KD, Ichinose F, Shin H-S, Shigematsu M, Bagchi A, et al. Activation of Toll-like receptor 2 impairs hypoxic pulmonary vasoconstriction in mice. Am J Physiol Lung Cell Mol Physiol. (2008) 294:L300-8. doi: 10.1152/ajplung.00243.2007

36. Ichinose F, Zapol WM, Sapirstein A, Ullrich R, Tager AM, Coggins $\mathrm{K}$, et al. Attenuation of hypoxic pulmonary vasoconstriction by endotoxemia requires 5-lipoxygenase in mice. Circ Res. (2001) 88:832-8. doi: 10.1161/hh0801.089177

37. Wadgaonkar R, Patel V, Grinkina N, Romano C, Liu J, Zhao Y, et al. Differential regulation of sphingosine kinases 1 and 2 in lung injury. Am J Physiol Lung Cell Mol Physiol. (2009) 296:L603-13. doi: 10.1152/ajplung.90357.2008
38. Lamort A-S, Giopanou I, Psallidas I, Stathopoulos GT. Osteopontin as a link between inflammation and cancer: the thorax in the spotlight. Cells. (2019) 8:815. doi: $10.3390 /$ cells 8080815

39. Rittling SR, Singh R. Osteopontin in immune-mediated diseases. J Dent Res. (2015) 94:1638-45. doi: 10.1177/0022034515605270

40. Takahashi F, Takahashi K, Shimizu K, Cui R, Tada N, Takahashi H, et al. Osteopontin is strongly expressed by alveolar macrophages in the lungs of acute respiratory distress syndrome. Lung. (2004) 182:173-85. doi: 10.1007/s00408-004-0309-1

41. Nau GJ, Guilfoile P, Chupp GL, Berman JS, Kim SJ, Kornfeld H, et al. A chemoattractant cytokine associated with granulomas in tuberculosis and silicosis. Proc Natl Acad Sci USA. (1997) 94:6414-9. doi: 10.1073/pnas.94.12.6414

42. O’Regan AW, Chupp GL, Lowry JA, Goetschkes M, Mulligan N, Berman JS. Osteopontin is associated with $\mathrm{T}$ cells in sarcoid granulomas and has $\mathrm{T}$ cell adhesive and cytokine-like properties in vitro. J Immunol. (1999) 162:1024-31.

43. Kelly MM, Leigh R, Gilpin SE, Cheng E, Martin GEM, Radford K, et al. Cellspecific gene expression in patients with usual interstitial pneumonia. Am J Respir Crit Care Med. (2006) 174:557-65. doi: 10.1164/rccm.200510-1648OC

44. Carlson I, Tognazzi K, Manseau EJ, Dvorak HF, Brown LF. Osteopontin is strongly expressed by histiocytes in granulomas of diverse etiology. Lab Invest. (1997) 77:103-8.

45. van der Windt GJW, Hoogendijk AJ, Schouten M, Hommes TJ, Vos AF de, Florquin S, et al. Osteopontin impairs host defense during pneumococcal pneumonia. J Infect Dis. (2011) 203:1850-8. doi: 10.1093/infdis/jir185

46. Simoes DCM, Xanthou G, Petrochilou K, Panoutsakopoulou V, Roussos C, Gratziou C. Osteopontin deficiency protects against airway remodeling and hyperresponsiveness in chronic asthma. Am J Respir Crit Care Med. (2009) 179:894-902. doi: 10.1164/rccm.200807-1081OC

47. Xanthou G, Alissafi T, Semitekolou M, Simoes DCM, Economidou E, Gaga $M$, et al. Osteopontin has a crucial role in allergic airway disease through regulation of dendritic cell subsets. Nat Med. (2007) 13:570-8. doi: $10.1038 / \mathrm{nm} 1580$

48. Kohan M, Breuer R, Berkman N. Osteopontin induces airway remodeling and lung fibroblast activation in a murine model of asthma. Am J Respir Cell Mol Biol. (2009) 41:290-6. doi: 10.1165/rcmb.2008-0307OC

49. Berman JS, Serlin D, Li X, Whitley G, Hayes J, Rishikof DC, et al. Altered bleomycin-induced lung fibrosis in osteopontin-deficient mice. Am J Physiol Lung Cell Mol Physiol. (2004) 286:L1311-8. doi: 10.1152/ajplung.00394.2003

50. Takahashi F, Takahashi K, Okazaki T, Maeda K, Ienaga H, Maeda M, et al. Role of osteopontin in the pathogenesis of bleomycin-induced pulmonary fibrosis. Am J Respir Cell Mol Biol. (2001) 24:264-71. doi: 10.1165/ajrcmb.24.3.4293

51. Ganguly K, Martin TM, Concel VJ, Upadhyay S, Bein K, Brant KA, et al. Secreted phosphoprotein 1 is a determinant of lung function development in mice. Am J Respir Cell Mol Biol. (2014) 51:637-51. doi: $10.1165 / \mathrm{rcmb} .2013-04710 \mathrm{C}$

Conflict of Interest: The authors declare that the research was conducted in the absence of any commercial or financial relationships that could be construed as a potential conflict of interest.

Copyright (C) 2020 Wepler, Preuss, Merz, Hartmann, Wachter, McCook, Vogt, Kress, Gröger, Fink, Scheuerle, Möller, Calzia, Burret, Radermacher, Tuckermann and Vettorazzi. This is an open-access article distributed under the terms of the Creative Commons Attribution License (CC BY). The use, distribution or reproduction in other forums is permitted, provided the original author(s) and the copyright owner(s) are credited and that the original publication in this journal is cited, in accordance with accepted academic practice. No use, distribution or reproduction is permitted which does not comply with these terms. 